\title{
AVALIAÇÃO DO POTENCIAL ANTICARCINOGÊNICO DO EXTRATO AQUOSO DE ROMÃ (PUNICA GRANATUM L.) POR MEIO DO TESTE PARA DETECÇÃO DE CLONES DE TUMORES EPITELIAIS (WARTS) EM DROSOPHILA MELANOGASTER
}

\author{
EVALUATION OF THE ANTICARCINOGENIC POTENTIAL OF POMERGRANATE \\ (PUNICA GRANATUM L.) AQUEOUS EXTRACT THROUGH THE TEST FOR \\ DETECTION OF EPITHELIAL TUMOR CLONES (WARTS) IN DROSOPHILA \\ MELANOGASTER
}

\author{
Bianca Duarte Araújo Santos, Brenda Najat Boechat Lahlou, Priscila Capelari Orsolin
}

Centro Universitário de Patos de Minas - UNIPAM

\begin{abstract}
The Pomegranate (Punica granatum L.), fruit belonging to the Lythraceae family and native to northwestern India, contains several bioactive compounds, such as anthocynins, tannins and phenolic acids. Its phytotherapic attributes involve an antimicrobial, anthelmintic, antioxidant and antiviral activity. This study seeks to analyze the anticarcinogenic effect of pomegranate aqueous extract, through the epithelial tumor (warts) detection in Drosophila melanogaster test. For this purpose, larvae $w t s+/+m w h$ were treated with the tumor inducer doxorubicin (0.4mM) and the aqueous extract of pomegranate in the proportions 1:8, 1:4 and 1:2, in isolation and in association with DXR. The results showed that pomegranate did not induce increase in tumor frequency, when compared to the negative control $(p>0,05)$. However, in combinations with doxorubicin, there was a statistically significant reduction $(p>0,05)$ in tumors induced by this chemotherapeutic agent. It is concluded that the aqueous extract of pomegranate, in the experimental conditions proposed in this study, was able to reduce the frequency of tumors, demonstrating their potential use in cancer prevention and therapy.
\end{abstract}

Key words: Punicaceae; Antineoplastic Agents; Drosophila melanogaster.

\section{Resumo}

A romã (Punica granatum L.), fruto pertencente á família Lytraceae e nativa do noroeste da Índia, contêm diversos compostos bioativos, como antocininas, taninos e ácidos fenólicos. Seus atributos fitoterápicos envolvem atuação antimicrobiana, anti-helmíntica, antioxidante $e$ antiviral. Este trabalho foi desenvolvido com o objetivo de analisar o efeito anticarcinogênico do extrato aquoso de romã, por meio do teste para detecção de clones de tumores epiteliais (warts) em Drosophila melanogaster. Para tanto, larvas $w t s+/+m w h$, foram tratadas com o indutor de tumor doxorrubicina $(0,4 \mathrm{mM})$ e com extrato aquoso de romã nas proporções 1:8, 1:4 e 1:2, isoladamente e em associação com DXR. Os resultados demonstraram que a romã não induziu aumento nas frequências de tumores, quando comparado ao controle negativo $(p>0,05)$. Porém, nas associações com a doxorrubicina verificaram-se reduções, estatisticamente significativas $(p<0,05)$, nos tumores induzidos por este quimioterápico. Conclui-se, portanto, que o extrato aquoso da romã, nas condições experimentais propostas neste estudo, foi capaz de reduzir a frequência de tumores em D. melanogaster, evidenciando seu potencial uso na prevenção e terapia do câncer.

Palavras chave: Punicaceae; anticarcinógenos; Drosophila melanogaster. 
Introdução

O câncer é uma multiplicação celular anômala, descontrolada e autônoma, no qual as células perdem ou reduzem a sua capacidade de diferenciação e estão propensas a invadir outras estruturas orgânicas em decorrência de modificação nos genes responsáveis pela regulação do crescimento e desenvolvimento celular $^{1,2}$. O número de casos de câncer vem crescendo em todo o mundo e já representa um problema de saúde pública, tanto nos países desenvolvidos, como naqueles em desenvolvimento. Na maioria das nações essa enfermidade ocupa o segundo lugar nas causas de óbitos mais comuns, perdendo apenas para as doenças cardiovasculares ${ }^{3,4}$.

Nesse contexto, a pesquisa de medicamentos anticancerígenos tem recebido incremento, a fim de se encontrar novos tratamentos mais seletivos e eficazes capazes de evitar o surgimento e a evolução da doença ${ }^{5}$. Dentre os fármacos derivados de fontes vegetais é ampla a quantidade e o progresso de pesquisas clínicas nas áreas dos antitumorais ${ }^{6}$. A Punica granitum L. (romã), fruta típica de várias tradições, tem sido alvo de investigações com o propósito de certificar suas propriedades medicinais relacionadas ao câncer ${ }^{7}$.

A $P$. granitum L. é um arbusto lenhoso, ramificado, nativa da região que abrange desde o Irã até o Himalaia, ao noroeste da Índia. Cresce em locais de clima árido, sendo que a sua frutificação ocorre entre os meses de setembro e fevereiro $^{8}$. Existem relatos das seguintes propriedades do fruto: antioxidante, hipoglicemiante, antivirótica, anti-helmíntica, antifúngica, antibacteriana, atenuação de fatores aterogênicos, reparação de feridas, atividade estrogênica e modulação das respostas antiinflamatórias ${ }^{7,8,9}$. Apesar de vários estudos já terem sido realizados com essa espécie, seus possíveis efeitos citotóxicos no homem ainda não são bem elucidados ${ }^{10}$.

O presente estudo foi desenvolvido com o objetivo principal de avaliar o potencial efeito anticarcinogênico do extrato aquoso de romã (Punica granatum L.) sobre o material genético, por meio da análise da sua influência sobre o surgimento e/ou regressão de tumores epiteliais em Drosophila melanogaster

\section{Metodologia}

O presente estudo é uma pesquisa experimental de natureza quantitativa. 0 organismo teste em questão (Drosophila melanogaster) é um invertebrado, sendo assim, prescinde à submissão ao Comitê de Ética em Pesquisa.

\subsection{AGENTES QUÍMICOS}

\subsubsection{Punica granatum L.}

As romãs foram obtidas em um jardim privado da cidade Patos de Minas-MG no mês de novembro de 2015. Após a coleta, os frutos foram encaminhados ao Herbário de Ensino e Pesquisa do Centro Universitário de Patos de Minas, Mandevilla sp. para identificação taxonômica da espécie, classificando-a como Punica granatum L., pertencente a família Lytraceae. sob o número de registro 219.3.6. Após a identificação, os frutos foram encaminhados ao Laboratório de Química do Centro Universitário de Patos de Minas, onde foram armazenados em recipientes de vidro com tampa até o momento da preparação dos extratos.

Para a confecção do extrato aquoso de Punica granatum L., as sementes e as cascas dos frutos foram picadas, adicionadas à água filtrada e fervida para, então, serem submetidas à trituração mecânica. Posteriormente, o extrato foi filtrado, acondicionado em frasco de vidro, embalado com papel alumínio e armazenado sob refrigeração $(4 \circ C)$ até o momento de utilização. 0 extrato foi preparado nas seguintes proporções: 1:8, 1:4 e 1:2 (polpa de romã: água).

2.1.1.1 Análise química do extrato aquoso de Punica granatum $L$.

A análise química do extrato de romã foi constituída pela mensuração da densidade, do potencial de hidrogênio $(\mathrm{pH})$, além da identificação do potencial antioxidante e da presença de metabólitos secundários.

A densidade foi calculada utilizando o picnômetro, de acordo com o método descrito por César et al. ${ }^{11}$, que relaciona a massa da água destilada com a do extrato em teste. Foi obtido um resultado igual a $1,02 \mathrm{~g} / \mathrm{mL}$.

A medida do $\mathrm{pH}$ foi realizada de acordo com a metodologia do Instituto Adolfo Lutz ${ }^{12}$. Pesouse $10 \mathrm{~g}$ de uma amostra de extrato seco de romã que foi diluída em $100 \mathrm{~mL}$ de água destilada e agitada. Posteriormente, foi colocada então no pHmetro para análise, revelando resultado igual a 3,8 .

Para avaliar a atividade antioxidante do extrato de romã foi utilizado o método 2,2 - 
difenil-1-picrilhidrazilo (DPPH) (CAS: 1898-66-4, Sigma-Aldrich Co. St. Louis, MO, EUA). O controle positivo utilizado foi a Rutina (CAS: 04.3131-1, Patos de Minas, MG, Brasil), a uma concentração final de $1 \mathrm{mg} / \mathrm{mL}$. A solução metanólica de DPPH foi preparada a uma concentração final de 40 $\mu \mathrm{g} / \mathrm{mL}$. A amostra do extrato metanólico de romã também foi preparada na concentração de $10 \mathrm{~g} / \mathrm{L}$.

$\mathrm{Na}$ avaliação antioxidante, $950 \mu \mathrm{L}$ de solução de DPPH foram misturadas com $50 \mu \mathrm{L}$ de extrato de romã ou rutina. O controle negativo foi obtido adicionando $50 \mu \mathrm{L}$ de metanol à solução de DPPH. Estas misturas foram incubadas durante $15 \mathrm{~min}$ em ambiente escuro a $30 \circ \mathrm{C}$. Em seguida, cada amostra de $1000 \mu \mathrm{L}$ foi transferida para um eppendorf (em triplicata) e levada ao espectrofotômetro para leitura. A redução na absorbância foi monitorada a 517 nm utilizando um leitor de microplacas ${ }^{13}$. O resultado do teste foi positivo para presença de antioxidantes no extrato de romã.

Para identificação dos flavonoides foi utilizada a Reação de Shinoda. No preparo do extrato etanólico, ferveu-se em banho-maria $1 \mathrm{~g}$ do extrato seco de romã com $10 \mathrm{~mL}$ de solução de $\mathrm{EtOH}$ a $70 \%$ por 2 min, sendo então filtrada com algodão. Adicionou-se $2 \mathrm{~mL}$ do extrato alcoólico em um tubo de ensaio juntamente com seis fitas de magnésio ( $\mathrm{Mg}$ metálico). Posteriormente, foi acrescentado $1 \mathrm{~mL}$ de $\mathrm{HCl}$ concentrado. Observou- se uma coloração avermelhada na solução, indicando um resultado positivo ${ }^{14}$.

A identificação de taninos foi realizada utilizando o método proposto por Matos ${ }^{15}$. Pesou-se 500,01g do pó do material seco de romã e acrescentou-se $1260 \mathrm{~mL}$ de etanol próanálise, sendo deixado em repouso por $72 \mathrm{~h}$. A mistura passou pelo método de filtração simples, foi concentrada em um rotaevaporador e, posteriormente, colocada em banho maria. Para o preparo da solução mãe pesou-se $0,3 \mathrm{~g}$ do extrato que foi diluído em $30 \mathrm{~mL}$ de álcool a $70 \%$. Adicionou-se uma gota da amostra hidratada a um papel filtro. Sobre a mesma, foi acrescentada uma gota de cloreto férrico à 0,5 M. Após alguns minutos foi observada coloração azul, demonstrando positividade do teste ${ }^{15}$.

\subsubsection{Doxorrubicina (DXR)}

O controle positivo utilizado para realização do experimento foi a Doxorrubicina (Adriblastina ${ }^{\circledR}$ ), antibiótico pertencente à classe das antraciclinas empregado na regressão de um amplo espectro de neoplasias ${ }^{16,17}$.

Apesar da ação antineoplásica da Doxorrubicina por meio da intercalação do DNA, estudos demonstram que seu uso pode levar ao surgimento de mutações e ao desenvolvimento de tumores. Isso ocorre devido à formação de adutos de estrutura complexa por ligações covalentes com o DNA, pontes inter e intracadeia e de radicais livres, justificando o seu uso como controle positivo na presente pesquisa ${ }^{16,18,19}$.

A Doxorrubicina utilizada é fabricada e embalada por Actavis Haly S.p.A, Itália (Registro: 1.0216.0165.002-4) e produzida pelo laboratório Pfizer. O referido composto foi utilizado na concentração de 0,4 mM, utilizando água osmose reversa como solvente.

\subsection{TESTE PARA DETECÇÃO DE TUMORES EPITELIAIS EM D. MELANOGASTER}

\subsubsection{Drosophila melanogaster}

A espécie Drosophila melanogaster, conhecida popularmente como "mosca-dasfrutas" é um invertebrado pertencente à família Drosophilidae, ordem Diptera, classe Insecta. A D. melanogaster é geneticamente bem explorada, sendo utilizada em estudos de genética desde 1906, já que seu genoma possui homologia de $60 \%$ com os genes de doenças humanas ${ }^{20}$.

Na larva da Drosophila existem grupos de células que darão origem, durante a metamorfose, às estruturas do corpo da mosca adulta, conhecidos como os discos imaginais. Esses discos possuem um ciclo celular muito similar aos das células de mamíferos. Um dos genes envolvidos na regulação do controle do ciclo celular é o wts (warts), gene da Drosophila, homólogo ao gene supressor de tumor LATS1 nos mamíferos. Por tais razões, o wts é o gene enfocado neste experimento ${ }^{21}$.

\subsubsection{Linhagens estoque, cruzamento e} tratamento

Duas linhagens mutantes de $D$. melanogaster foram empregadas na realização desse teste: Linhagem wts e Linhagem multiple wing hairs $(m w h)$. Os estoques contendo essas linhagens são mantidos no Laboratório de Citogenética e Mutagênese do Centro Universitário de Patos de Minas em frascos de $1 / 4$ de litro contendo meio de cultura para $D$. melanogaster, à temperatura de $25 \circ \mathrm{C}$ e $60 \%$ de umidade.

Para realização do experimento foi efetuado o cruzamento entre fêmeas virgens wts/TM3 Sb1 com machos $\mathrm{mwh} / \mathrm{mwh}$. A coleta de ovos dos descendentes do cruzamento 
ocorreu durante um período de 8 horas. Após $48 \pm 4$ horas as larvas foram lavadas com água osmose reversa e coletadas com o auxílio de uma peneira de malha fina.

As larvas de 3 estágio foram submetidas a um tratamento crônico (aproximadamente 48 horas). Para tanto, foram dispostas em frascos de vidro contendo $1,5 \mathrm{~g}$ de purê de batatas (meio alternativo para Drosophila) juntamente com as três concentrações (proporções) do extrato aquoso de romã $(1: 8,1: 4$ e 1:2). Em outros frascos, também contendo purê de batata na mesma quantidade, foram acrescentadas as concentrações testadas do extrato aquoso de romã juntamente com o quimioterápico doxorrubicina, em sistema de cotratamento (exposição simultânea). Para o controle negativo foi água osmose reversa e para controle positivo, doxorrubicina $(0,4 \mathrm{mM})$.

Todo tratamento foi efetuado em quatro séries (repetições) independentes, sendo os indivíduos agrupados para análise dos resultados após verificação de que os experimentos apresentavam reprodutibilidade aceitável.

\subsubsection{Análise das moscas}

Ocorrido o tratamento, as moscas foram armazenadas em frascos devidamente identificados, contendo etanol $70 \%$. Em seguida, foram individualmente colocadas em uma placa escavada contendo glicerina e, através de uma lupa estereoscópica, foram analisadas quanto à presença de tumores.

Todas as moscas foram coletadas, porém aquelas que apresentam pelos curtos e grossos foram descartadas posteriormente por não possuírem o gene wts. Sendo assim, apenas as moscas adultas com genótipo ( $w t s+/+m w h$ ), que possuem pelos fenotipicamente selvagens (longos e finos) foram analisadas.

\subsubsection{Análise estatística}

As diferenças estatísticas, entre as frequências de tumores encontradas nas diferentes concentrações testadas e os controles, foram calculadas utilizando o teste $U$, não paramétrico, de Mann-Whitney, empregando o nível de significância de $5 \%$.

\section{Resultados e Discussões}

Os resultados da avaliação do potencial anticarcinogênico do extrato aquoso de romã estão apresentados na Tabela 1, que demonstra a frequência de clones de tumores por segmentos do corpo da D. melanogaster.

Tabela 1. Frequência de clones de tumores observados em Drosophila melanogaster, heterozigota para o gene supressor de tumor wts, tratadas com doxorrubicina e diferentes concentrações de extrato de Romã.

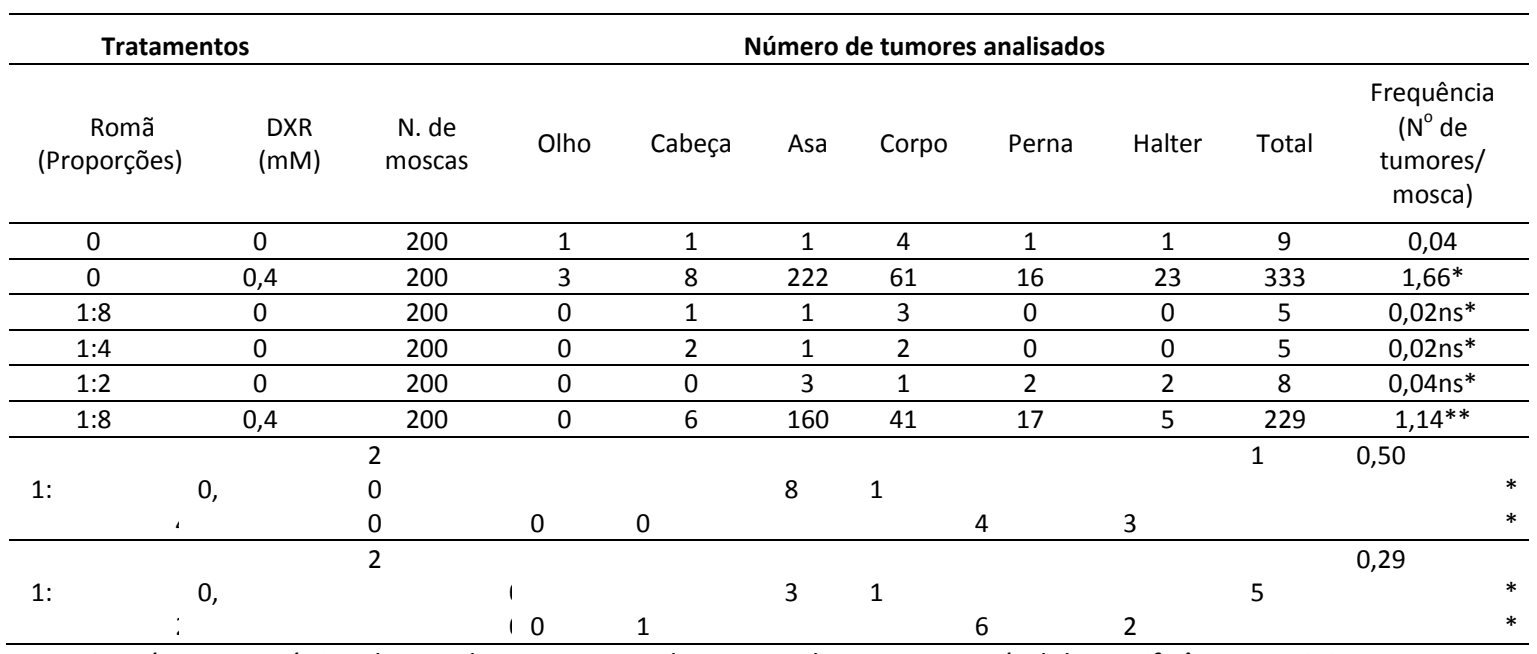

Diagnóstico estatístico de acordo com o Teste de Mann-Whitney Teste. Nível de significância $p \leq 0,05$

* Valor considerado diferente do controle negativo $(p \leq 0,05)$.

** Valor considerado diferente do controle positivo (DXR 0,4 mM) $(p \leq 0,05)$.

$n s^{*}$, valores considerados não significativos, quando comparados com o controle negativo.

DXR, doxorrubicina. 
Como pode ser observado, o extrato testado exerceu efeito anticarcinogênico nas concentrações 1:8, 1:4 e 1:2, uma vez que nas três proporções testadas houve redução na frequência total de tumores $(p<0,05)$, quando comparado ao controle positivo isolado (DXR 0,4 $\mathrm{mM}$ ), no qual foi observada frequência de 1,66 tumores por mosca. Naqueles descendentes tratados com o extrato aquoso de romã (nas diferentes concentrações) em associação com a Doxorrubicina foram verificadas, respectivamente, frequências totais de 1,14; 0,50 e 0,29 tumores por mosca. Assim sendo, evidencia-se que o extrato aquoso de romã foi capaz de atuar na redução de tumores induzidos pela DXR. Foi demonstrado, também, que o efeito apresentou relação dose dependente, já que a frequência de tumores foi reduzindo à medida que houve aumento na concentração de extrato utilizado.

Ainda por meio da Tabela 1 é possível constatar que o referido extrato não apresentou efeito carcinogênico (indutor de tumor), diante do modelo experimental utilizado, em nenhuma das concentrações testadas, uma vez que as frequências totais nas concentrações isoladas $(1: 8,1: 4$ e 1:2) foram, respectivamente, 0,02; 0,02 e 0,04 , não havendo diferença estatisticamente significativa $(p>0,05)$ quando comparado ao controle negativo isolado (água osmose reversa).

Para os indivíduos tratados com o controle negativo verificou-se uma frequência de 0,04 tumores por mosca. Enquanto isso, no controle positivo constatou-se uma frequência de 1,66 tumores por mosca, demonstrando que a espécie teste é sensível à indução tumoral.

Os mecanismos responsáveis pelos efeitos anticarcinogênicos do extrato de romã não foram diretamente analisados no presente estudo. Entretanto, várias pesquisas realizadas com esse fruto comprovaram efeitos antioxidantes, próapoptóticos, antiangiogênicos, anti-inflamatórios, antiandrogênicos, bem como efeitos inibidores da invasão e proliferação celulares, relacionados a ação antitumoral ${ }^{22,23,24}$.

A romã é composta por um alto teor de flavonoides e polifenois. Entre os compostos fenólicos, apresenta: antocianinas, quercetina, ácidos fenólicos e taninos ${ }^{9,22,25,26}$. Segundo Jardini e Mancini Filho ${ }^{23}$, os compostos fenólicos presentes na polpa e sementes da romã apresentam potente atividade antioxidante. Além disso, estudo realizado por Shiban et al. ${ }^{25}$ demonstrou propriedade semelhante nos fenólicos extraídos da casca. Os flavonoides também apresentam capacidade de combater substâncias oxidantes ${ }^{7,27}$. A maioria desses compostos estão localizados na casca e no pericarpo da fruta ${ }^{22}$.

Os antioxidantes agem em níveis diferentes a fim de proteger o organismo: impedindo a formação de radicais livres, capturando radicais livres gerados pelas fontes endógenas ou exógenas e reparando danos gerados pelos próprios radicais livres ${ }^{28}$. Estes também podem exercer modulação positiva do sistema de defesa antioxidante endógeno (superóxido dismutase, catalase e glutationa peroxidase) ${ }^{26}$.

Os radicais livres causam ataque aos lipídios, aminoácidos, ácidos graxos poliinsaturados e às bases do DNA, podendo ocasionar a multiplicação celular sem reparos. Assim, as substâncias antioxidantes, tais como os compostos da romã, previnem a perda da integridade celular e a formação de lesões e mutações, $^{28,29,30}$.

Foi constatado um potencial efeito antioxidante do Punica granatum L. no estudo de Kumar et al. $^{31}$ que induziu uma redução de peroxidação lipídica em encéfalos de camundongos após tratamento com o extrato da fruta. Em outro trabalho, desenvolvido por Constantini e colaboradores ${ }^{24}$, o extrato de metanol a $80 \%$, retirado do óleo da semente da romã expressou percentagem de sequestro e inibição do radical livre DPPH (2,2-difenil-1picrilhidrazil) de $96,8 \%$, testado em vitro.

Outra atuação dos componentes da romã, que poderia justificar os resultados obtidos na presente pesquisa, refere-se à indução de apoptose, processo de morte celular fisiologicamente programado. Sangeetha e Vijayalakshimi ${ }^{32}$ testaram o extrato da casca da romã em células de câncer pulmonar da linhagem A59. $\mathrm{Na}$ análise morfológica, a linhagem tratada com a fração de acetato de etila $(25 \mu \mathrm{g} / \mathrm{ml})$ e a de álcool $(50 \mu \mathrm{g} / \mathrm{ml})$ do extrato, após 48 horas, possuía características típicas de células apoptóticas.

Estudo desenvolvido por Begum e $\mathrm{Kumar}^{33}$ identificou um efeito citotóxico, por meio de uma redução dose dependente na quantidade de células de câncer de mama da linhagem MCF-7 quando tratadas com extrato de Punica granatum L. Além disso, estudo de Constantini et al. $^{24}$ constatou diminuição de viabilidade das linhagens MCF-7 e MDA-MB-231, tratadas com componentes da fração hidrofílica do óleo da semente da fruta. Essa reação foi associada a um aumento da duração das fases G0/G1 do ciclo celular, crucial para indução de parada do ciclo por proteínas reguladoras, caso ocorram mutações. 
O extrato da Punica granatum L. também atua inibindo o crescimento celular tumoral. Malik et al. $^{34}$ testaram os efeitos antiproliferativos do extrato de romã em células cancerígenas prostáticas PC3 e verificaram uma redução dose dependente do crescimento celular de PC3. Também foi encontrado efeito similar em células MCF-7 e MB-MDA-231 do câncer mamário e B16F10 de melanoma ${ }^{35,36}$.

Flavonoides estrogênicos não-esteroidais possuem um efeito estrogênico com ação competitiva no receptor do $17-\beta$-estradiol ${ }^{22}$. Maru et al. ${ }^{37}$ confirmaram esse efeito similar ao estrogênio nos compostos do suco de romã, por meio da apresentação de ação proliferativa em células de câncer de mama MCF-7 e um aumento no peso uterino de camundongos ooferectomizados tratados com extrato.

Essa atividade estrogênica pode possuir potencial terapêutico antitumoral por inibir atividade androgênica em neoplasias dependentes desse hormônio, por mecanismos anti-inflamatórios e por promoção de apoptose, através das vias Fas $/ \mathrm{FasL}^{38}$. A ação antiandrogênica da romã pode ser exercida, também, pela redução da expressão de receptor androgênico (AR) em células de câncer prostático, da linhagem CWR22Rv1, como demonstrado em experimento desenvolvido por Malik et al. ${ }^{34}$

Outra importante ação da romã é a atividade anti-inflamatória, como confirmado em experimento de González-Trujano et al. ${ }^{39}$, em que o substrato da fruta induziu a redução de lesões gástricas provocadas por indometacina e por etanol. Na pesquisa de Constantini et al. ${ }^{24}$ foi constatada uma redução dose dependente de citocinas expressadas nas células MCF-7 e MDAMB-231 do câncer mamário, sendo elas: IL-2, IL6, IL-12, IL-17, IP-10, MIP-1 $\alpha$, MIP-1 $\beta$, MCP-1 e TNF- $\alpha$, demonstrando envolvimento de um efeito antiinflamatório na inibição do processo tumoral $^{22,24}$.

A angiogênese, compreendida como iniciação e desenvolvimento de novos vasos sanguíneos, é responsável pelo suprimento de oxigênio e nutrientes para o crescimento tumoral e metástase ${ }^{22}$. Pesquisas mostraram que polifenois presentes em diferentes substâncias antioxidantes exercem inibição da angiogênese, levando à dedução de que o mesmo possa ocorrer com os compostos fenólicos da romã ${ }^{40,41}$.

A via de sinalização do Fator de Crescimento do Endotélio Vascular (VEGF) é o principal mediador na neovascularização tumoral $^{36}$. Toi et al. ${ }^{42}$ observaram que os substratos da romã, testados em células endoteliais de veia umbilical humana (HUVEC), exerceram efeitos antiproliferativos sobre células angiogênicas. $O$ estudo também comprovou que os substratos da Punica granatum L. levaram à infrarregulação acentuada de VEGF em células de neoplasia mamária MCF-10A e MCF-7. Dana et al. $^{36}$ obtiveram resultados semelhantes, no qual se identificou uma inibição dose dependente da expressão de RNAm de VEGF e uma supressão na formação dos tubos pelas células endoteliais em HUVECS.

O próprio efeito anti-inflamatório do extrato, descrito anteriormente, contribui para inibição da angiogênese. Como exemplo, a citocina IL-6, além de suas ações relacionadas ao processo inflamatório, estimula a secreção de VEGF em células cancerosas ${ }^{24}$ e os componentes da romã levam à redução desse e de outros fatores ligados indiretamente à angiogênese.

Conclui-se, portanto, que o extrato aquoso de Punica granatum L. não possui efeito indutor neoplásico em $D$. melanogaster, nas presentes condições experimentais e, ao contrário, exerceu ação anticarcinogênica, já que foi demonstrada uma redução significativa e dose dependente da frequência dos tumores em todas as concentrações testadas em associação com o controle positivo doxorrubicina. Tais resultados podem ser embasados por mecanismos descritos em outras pesquisas relatadas na literatura, com destaque aos efeitos antioxidante, próapoptótico, antiangiogênico, anti-inflamatório e inibidor de proliferação celular, atuando em sinergismo.

Assim, evidencia-se o potencial uso terapêutico do extrato aquoso da romã na prevenção e terapia do câncer. Entretanto, novas investigações utilizando outros organismos e outros modelos experimentais são essenciais para a maior compreensão da atuação dos constituintes do extrato aquoso de romã e da sua repercussão sobre a medicina oncológica.

\section{Conclusão}

Neste estudo observou-se alta prevalência de aborto e de cesarianas num hospital público do interior da Bahia. Observou-se que as mulheres submetidas ao parto cesáreo e as que abortaram permaneceram mais tempo internadas no hospital. Esse cenário aponta para desconformidade com relação a orientações da Organização Mundial de Saúde e do próprio Ministério da Saúde, o que pode impactar em aumento de custos e maiores riscos à saúde materno-infantil. Esses dados demonstram a necessidade do fortalecimento de políticas 
públicas para incentivo ao parto natural e classificação das gestantes quanto risco obstétrico.

\section{Referências}

1. Brasileiro Filho, G. Bogliolo: Patologia. 8.ed. Rio de Janeiro: Editora Guanabara Koogan; 2011.

2. Inca: Instituto Nacional do Câncer. Ministério da Saúde. O que é o câncer? [Citado 2015 Fev 17] Disponível em: http://www1.inca.gov.br/conteudo view.asp?id=322.

3. Pan, R.; Marques, A. R.; Costa Júnior, M. L.; Nascimento, L. C. Caracterização das internações hospitalares de crianças e adolescentes com neoplasias. Revista Latinoamericana de Enfermagem. 2011; 19(6): 1-8.

4. Malta, D. C.; Moura, L.; Prado, R. R.; Escalante, J. C.; Schmidt, M. I.; Duncan, B. B. Mortalidade por doenças crônicas não transmissíveis no Brasil e suas regiões, 2000 a 2011. Epidemiologia e Serviços de Saúde. 2014; 23(4): 599-608.

5. Brandão, H. N. Química e farmacologia de quimioterápicos antineoplásicos derivados de plantas. Química Nova. 2010; 33(6):1359-1369.

6. Silva, P. Farmacologia. 8.ed. Rio de Janeiro: Editora Guanabara Koogan, 1998.

7. Werkman, C. Aplicações terapêuticas da Punica granatum L. (romã). Revista Brasileira de Cancerologia. 2008; 10(3): 104-111.

8. Jardini, F. A. Avaliação da atividade antioxidante da romã (Punica granatum L.) Participação das frações de ácidos fenólicos no processo de inibição da oxidação. [Dissertação]. [São Paulo]: Programa de pós-graduação em Ciência dos Alimentos, Faculdade de Ciências Farmacêuticas da Universidade de São Paulo; 2005. $129 \mathrm{p}$.

9. Santos, E. H. B.; Batista, F. P. R.; Pereira, L. M.; Campos, L. M. A.; Castro, M. S.; Azevêdo, L.

C. Composição físico-química dos frutos de romã (Punica granatum L.). [Citado 2015 Mar 05] Disponível em:

http://www.almanaquedocampo.com.br /imagens/files/ Rom\%C3\%A3.pdf.

10. Werkman, C. Citotoxidade da Punica Granatum L. (romã) sobre cultura de fibroblastos e de células de linhagem cancerígena. [Tese]. [São José dos Campos]: Programa de PósGraduação em Biopatologia Bucal, Universidade Estadual Paulista; 2009. 115 p.
11. César, J.; De Paoli, M. A.; De Andrade, J.; C. A determinação da densidade de sólidos e líquidos. Chemkeys. 2004; 1-8.

12. Instituto Adolfo Lutz. Normas Analíticas do Instituto Adolfo Lutz. v.1: Métodos químicos e físicos para análise de alimentos. 3 ed. São Paulo: IMESP; 1985.

13. Mishra, K.; Ojha, H.; Chaudhury, N. K. Estimation of antiradical properties of antioxidants using DPPH assay: a critical review and results. Food Chemistry. 2012; 130(4): 10361043.

14. Oliveira, G. L. S.; Castro, L. M. R.; Rocha, P. R. S.; Santos, F. J. B.; Resende, M. Identificação de Metabólitos Secundários da Casca da Bauhinia forficata platypetala e Bauhinia unguiculata. V Congresso de Pesquisa e Inovação da Rede Norte Nordeste de Educação Tecnológica. 2010, nov. 17-19. Maceió: Instituto Federal de Educação, Ciência e Tecnologia da Bahia; 2010.

15. Matos, F. J. A., Introdução a fotoquímica experimental. 3.ed. Fortaleza: Edicões UFC; 2009. 16. Almeida, V. L.; Leitão, A.; Reina, L. C. B.; Montanari, C. A.; Donnici, C. L.; Lopes, M. T. P. Câncer e agentes antineoplásicos ciclo-celular específicos e ciclo-celular não específicos que interagem com o DNA: uma introdução. Química Nova. 2005; 28(1): 118-129.

17. Craig, C. R.; Stitzel, R. E. Farmacologia moderna: com aplicações clínicas. 6.ed. Rio de Janeiro: Editora Guanabara Koogan, 2005.

18. Carvalho, V. M. Adutos de DNA gerados por produtos da lipoperoxidação: caracterização, detecção, incorporação em oligonucleotídeos e implicações biológicas. [Tese], [São Paulo]: Instituto de Química da Universidade de São Paulo; 2001. 236 p.

19. Souza, L. M. Avaliação da indução de senescência e apoptose pelo tratamento com atraciclinas em fibroblastos humanos deficientes no reparo por excisão de nucleotídeos. [Trabalho de Conclusão de Curso]. [Porto Alegre]: Universidade Federal do Rio Grande do Sul; 2011. $46 \mathrm{p}$.

20. Toni, D. C.; Hofmann, P. R. P.; ValenteGaiesky, V. L. S., Polimorfismos de pigmentação em Drosophila. Naturalia. 2002; 27: 231-243.

21. Eeken, J. C. J; Klink, I; Veen, B. L. V; Pastink, A; Ferro, W. Induction of epithelial tumors in Drosophila melanogaster heterozygous for the tumor suppressor gene wts. Environmental and Molecular Mutagenesis. 2002; 40(4):277-282.

22. Lansky, E. P.; Newman, R. A. Punica granatum (pomegranate) and its potential for prevention and treatment of inflammation and 
cancer. Journal of Ethnopharmacology. 2007; 109 (2): 177- 206.

23. Jardini, F. A; Mancini Filho, J. Avaliação da atividade antioxidante em diferentes extratos da polpa e sementes da romã (Punica granatum L.). Revista Brasileira de Ciências Farmacêuticas. 2007; 43(1): 137-147.

24. Constantini, S.; Rusolo F.; De Vito V.; Moccia S.; Picariello G., Capone F.; et al. Potential anti-inflammatory effects of the hydrophilic fraction of Pomegranate (Punica granatum L.) seed oil on Breast Cancer Cell Lines. Molecules, 2014; 19(6): 8644-8660.

25. Shiban, M.; Al-Otaibi, M.; Al-Zoreky, N. Antioxidant activity of pomegranate (Punica granatum L.) fruit peels. Food and Nutrition Sciences. 2012; 3(7): 991-996.

26. Santiago, M. C. P. A. S.; Avaliação de Processos para Obtenção de Produtos Ricos em Antocianinas Utilizando Suco de Romã (Punica granatum L.). [Tese], [Rio de Janeiro]: Escola de Química, Universidade Federal do Rio de Janeiro. 2014. 137p.

27. Flambó, D. F. A. L. P. Atividades biológicas dos flavonoides: atividade antimicrobiana. [Dissertação], [Porto]: Faculdade de Ciências da Saúde, Universidade Fernando Pessoa. 2013. 31p.

28. Bianchi, M. L.; Antunes, L. M. G. Radicais livres e os principais antioxidantes da dieta. Revista de Nutrição.1999; 12(2): 123-130.

29. Dornas, W. C.; Oliveira, T. T.; Rodrigues, R.G.; Santos, A .F.; Nagem, T. J. Flavonoides: potencial terapêutico no estresse oxidativo. Revista de Ciências Farmacêuticas Básica e Aplicada. 2007; 28(3): 241-249.

30. Jardini, F. A. Atividade dos compostos fenólicos antioxidantes da romã (Punica granatum L.) - Avaliação in vivo e em culturas de células. 2010. [Tese], [São Paulo]: Faculdade de Ciências Farmacêuticas, Universidade de São Paulo, 2010. 93p.

31. Kumar, S.; Maheshwari, K. K.; Singh, V. Protective effects of Punica granatum seeds extract against aging and scopolamine induced cognitive impairments in mice. 2008; 6 (1): 49-56. 32. Sangeetha, J.; Vijayalakshimi, K. Apoptosis Induction of Punica Granatum Extract on Human Lung Cancer Cells. American Journal of Pharamtech Research. 2015, 5(1): 478-485.

33. Begum, Z.; Kumar, N. Evaluation of cytotoxic effect of Punica granatum L. var spinosa extracts on malignant cell line MCF-7 in vitro. Molecular Enzymology and Drug Targets, 2015; 1(1):1-6.
34. Malik, A.; Afaq, F.; Sarfaraz, S.; Adhami, V.M.; Syed, D.N.; Mukhtar, H. Pomegranate fruit juice for chemoprevention and chemotherapy of prostate cancer. Proceedings of the National Academy of Sciences of the United States of America. 2005; 102(41): 14813-14818.

35. Kim, N. D.; Mehta, R.; Yu, W.; Neeman, I.; Livney, T.; Amichay, A.; Poirier, D.; et al. Chemopreventive and adjuvant therapeutic potential of pomegranate (Punica granatum) for human breast cancer. Breast Cancer Research and Treatment. 2002; 71(3): 203-217.

36. Dana, N.; Javanmard, S. H.; Rafiee, L.; Antiangiogenic and antiproliferative effects of black pomegranate peel extract on melanoma cell line. Research in Pharmaceutical Sciences. 2015; 10(2):117-124.

37. Maru, I.; Ohnishi, J.; Yamaguchi, S.; Oda, Y.; Kakehi, K.; Ohta, Y. An Estrogen-like activity in pomegranate juice. Nippon Shokuhin Kagaku Kogaku Kaishi. 2001; 48(2):146-149.

38. Song, R. X.; Santen, R. J. Apoptotic action of estrogen. Apoptosis. 2003; 8(1): 55-60.

39. González-Trujano, M. E.; Pellicer, F.; Mena, P.; Moreno, D. A.; García-Viguera, C. Antinociceptive and anti-inflammatory activities of a pomegranate (Punica granatum L.) extract rich in ellagitannins. International Journal of Nutrition and Food Sciences. 2015; 66(4):1-5.

40. Ejaz, A.; Wu, D.; Meydani, M. Curcumin Inhibits Adipogenesis in 3T3-L1 Adipocytes and Angiogenesis and Obesity in C57/BL Mice. The Journal of Nutrition. 2009; 139(5): 919-925.

41. Kidd, P. Bioavailability and activity of phytosome complexes from botanical polyphenols: the silymarin, curcumin, green tea, and grape seed extracts. Alternative Medicine Review. 2009; 14(3):226-246.

42. Toi, M.; Bando, H.; Ramachandran, C.; Melnick, S. J.; Imai, A.; Fife, R. S.; et al. Preliminary studies on the anti-angiogenic potential of pomegranate fractions in vitro and in vivo. Aniogenesis. 2003; 6(2): 121-128. 


\section{Endereço para Correspondência}

Centro Universitário de Patos de Minas UNIPAM

R. Maj. Gote, 808 - Caiçaras, Patos de Minas - MG

CEP.: $38700-207$

e-mail biancaduartesantos@hotmail.com

Recebido em 05/06/2017

Aprovado em 09/11/2017

Publicado em 30/03/2018 